\title{
The Impact of Online Problem-Based Mentoring Programme on Postgraduate Orthopaedics Exam Performance-A Re-Audit of a Previous Study
}

\author{
Firas Arnaout ${ }^{1 *}$, Farhan Syed ${ }^{2}$, Husam Elbana ${ }^{3}$ and Shwan Fryad Henari ${ }^{4}$ \\ ${ }^{1}$ Senior Clinical Fellow in Trauma \& Orthopaedics, Royal Wolverhampton NHS Trust, UK \\ ${ }^{2}$ Clinical Trauma Fellow, University Hospital Coventry \&Warwickshire, UK \\ ${ }^{3}$ Speciality Doctor Trauma \& Orthopaedics, University Hospitals of Morecambe Bay, UK \\ ${ }^{4}$ Speciality Doctor in Trauma \& Orthopaedics, Horton General Hospital, Oxford University Hospitals Foundation Trust, UK
}

Submission: August 14, 2018; Published: September 07, 2018

*Corresponding author: Firas Arnaout,Senior Clinical Fellow in Trauma \& Orthopaedics, Royal Wolverhampton NHS Trust,

Email: firasarnaout@doctors.org.uk

\begin{abstract}
Discrepancy in Intercollegiate Fellowship of the Royal Colleges of Surgeons (FRCS) Trauma \& Orthopaedics (T\&0) exit exam passing rates between trainees \& career grade orthopaedic surgeons has been well established and accepted for a long time. This has been thought a consequence of the lack of access to a structured teaching program, which renders the career-grade surgeons less likely to meet the exam standards. A problem-based teaching system has been implemented. Exam pass results for trainee and career-grade surgeons published on the Joint committee of Intercollegiate Examination (JCIE) website, before and after implementing the career-grade teaching programme are extracted, analysed and percentages calculated, to explore if there was any effect and to which degree.The analysis showed an impressive improvement in career-grade surgeons' passing rate after establishing the teaching activities, with more than doubling of the pass rate.The findings of this audit strongly call for re-exploration of the current career-grade teaching opportunities, and the introduction of a regular teaching platform.
\end{abstract}

Keywords: FRCS; CESR; Training;Career grade

\section{Introduction}

Intercollegiate Fellowship of the Royal Colleges of Surgeons, Trauma \& Orthopaedics (FRCS Tr \& Orth) is a prestigious qualification and is a prerequisite for all the trauma and orthopaedic surgeons working in the UK and looking for a more senior role.It has worldwide recognition and considered to be one of the toughest exams in medicine. Success in the exam leads to the award of FRCS Tr \& Orth, which is one the requirements for the award of Certificate of Eligibility for Specialist Registration (CESR) [1]. It allows the candidate to demonstrate that they have attained the standard of competence required of a newly appointed Trauma \& Orthopaedic Consultant in the United Kingdom's National Health Service. The examinations are regulated by the Joint Committee on Intercollegiate Examinations (JCIE) on behalf of the four Royal Colleges of Surgeons Great Britain and Ireland. Those aspiring to do the exam wish to accomplish recognition and career progression. However, there is no doubt that this is a potentially stressful time for surgeons to achieve this career milestone alongside a busy job and personal life. This stress is further accentuated by the expensive exam fees of around $£ 2000$ and essential revision courses, which have a significant financial bearing on the candidates.
The FRCS exam is composed of oral and clinical components which require significant presentation skills and ability to perform focused clinical examination under time constraints. The surgeons who are not in a formal training programme face additional challenges due to lack of support, deficient career advice and lack of focused clinical training. Postgraduate medical education is currently carrying a health warning because of the stress and anxiety caused to doctors [2]. Therefore, any educational process that promotes engagement, interaction and a focused approach to learning is likely to improve the success rate.It is a much-needed step in the right direction [3].

Historically, there has been a significant gap between the pass rate of training and career grades in the UK [4]. It is hypothesised that lack of access to structured teaching programme and the absence of exam-oriented teaching contribute towards the relatively poor outcomes.Although the complexities of surgical care have increased dramatically over the last century, the methods of delivering training have changed little. Particularly for those outside of national training programmes.In a problembased curriculum, surgeons learn by actively solving problems, rather than by passively absorbing information. Surgeons must 
actively participate in their own education [3].We achieve this by a creating a peer to peer interface, through a multiplatform approach to complete the curriculum, using practice exam question to start the revision process on a topic, followed by both large group interactive session and small group viva sessions based on specific topics.

In this audit, our objective was to evaluate the pass rate of career-grade surgeons undertaking the FRCS exit examination who participated, in the peer-assisted and problem-based teaching designed by a group of career-grade grade surgeons who have been successful in completing the exit exam. The results are compared with the pass rate of trainees in a national training programme.To our knowledge there has not been any similar multiplatform, peer to peer, self-directed and problembased learning programme within the UK or the world for Surgeons.

\section{Methods}

For the initial audit, we extracted exam results for trainee and career-grade surgeons published on the JCIE website for February 2016 and May 2016 [4]. These two exam sittings were prior to the start of the educational system for career-grade surgeons.Data collected included the total number of careergrade and trainees who appeared in the exam, and the total number of career-grades and trainees who passed the exam. For the purposes of this Auditthe pass rate of trainees has been used as the standards for comparison as it has been maintained at a high level over many years.To overcome some of the above challenges, we introduced surgeon-focused mentoring platform as discussed earlier and re-evaluated the pass rate in Nov 2017, Feb 2018 and April 2018.

We then compared the results after the introduction of our problem-based teaching programme, designed specifically for surgeons who are not in the national training programme.

Our problem-based teaching system includes several constituents:

i. A communication platform using Telegram $\AA$ app. This became the largest community of career-grade orthopaedic surgeons in the UK preparing for the FRCS exam, with around 400 members at various stages of exam preparation, from people preparing for part 1 to people who have already passed.

ii. This allowed prospective exam candidates to correspond directly with previous successful candidates who have been through the similar experience. The successful candidates were able to give valuable advice on how to prepare for the exam, practical tips, sharing of educational materials, the recommendation of courses to attend as well as coaching. Membership in this group is free of charge, and invitation based on recommendation by existing members. iii. Comprehensive FRCS revision notes that have been written and developed by faculty who are members of the group, specifically aiming at exam candidates. These notes were provided electronically free of charge.

iv. Introduction to a series of weekly webinars and online conferencing sessions, delivered and facilitated by keen and competent mentors. Candidates were invited to attend and were given the opportunity to interact with the presenters. Appropriate sessions have been recorded and shared with the wider audience. Once again, this facility was also provided free of charge. The only motivation for mentors is to make a positive contribution to the educational development of their colleagues.

v. The average weekly attendance was ranging from 5060 participants from 12 different countries.

vi. The mentors are a group of post FRCS surgeons with good knowledge of the exam and who continue to show interest in FRCS relevant education.

vii. Small group Skype (C)viva sessions.

viii. Following the introduction of the above teaching methods, we re-audited the FRCS exam results. We collected the same above data about trainees from the JCIE website and compared those to the results of the members of our group who took part in the above coaching scheme. The results were collected by asking each member who attempted the exam to declare if they passed or failed. We also compared results with other career-grades surgeons who were not members of the coaching group. Their results were obtained from the JCIE website.

ix. Number of participants enrolled in study were naturally dictated by the number of members in group that felt ready to proceed to the exam, it was felt the by demonstrating consistent improvement in the outcome of the members from our group we can demonstrate the efficacy of this programme.As this was an observational study, the comparison of cohorts was the preferred method.

x. Personal data on participants within the group and those outside was not collected.There was no monitoring of preparedness to take the exam within group as this was felt to be outside the parameters of self-directed own pace learning.Also due to the voluntary nature of both those providing direction and teaching freely, and those participating in all capacities, the use of targets would not be helpful in maintaining the enthusiasm and0 good will of those who have passed the exam to remain and become the new mentors

\section{Results}

The first audit results are demonstrated in the table below (Table 1). These results show a significant difference in the pass 
rate between trainees and career grades.To overcome some of the above challenges, we introduced surgeon-focused mentoring platform as discussed earlier and re-evaluated the pass rate in Nov 2017, Feb 2018 and April 2018.From our group 7 out of 14 passed in Nov 2017, 11 out of 15 passed in Feb 2018 and 9 out of 19 in April 2018.

Table 1: passing results of the FRCS exam comparing career-grades to trainees in Feb \& May 2016 i.e. prior to the implementation of the new teaching method.

\begin{tabular}{|c|c|c|}
\hline & Career-grades & Trainees \\
\hline Total number sitting exam & 116 & 158 \\
\hline Total number who passed & 34 & 132 \\
\hline Percentage & $29.3 \%$ & $83.5 \%$ \\
\hline
\end{tabular}

The re-audit results are summarised in the table below (Table 2). The results of the audit loop closure show significant improvement in the pass rates of non-trainee surgeons undertaking the FRCS (TR\&Orth) exam after being supported by a mentoring programme, with an impressive increase from $29.3 \%$ to $56.2 \%$.Chi square test on the pass rates among careergrades in and outside the group shows a statistically significant positive outcome for those is the group ( $p$ value 0.006 ). This shows a narrowing of the gap between trainees and careergrades.It also shows that career-grades who followed the mentoring scheme have much better chance of being successful than those who didn't.Feedbacks collected from candidates after the interactive webinar sessions \& the experience they shared following their success emphasised the fact that problem-based learning curriculum and access to the support provided, have facilitated their learning and their eventual success, even those who had not passed felt supported and felt their performance had improved.

Table 2: passing results of the FRCS exam comparing careergrades to trainees in Nov 2017 \& Feb 2018 \& Apr 2018 i.e. after the implementation of the new teaching method.

\begin{tabular}{|c|c|c|c|}
\hline & $\begin{array}{c}\text { Career-grades } \\
\text { (in the group) }\end{array}$ & $\begin{array}{c}\text { Career-grades (out } \\
\text { of the group) }\end{array}$ & Trainees \\
\hline $\begin{array}{c}\text { Total number } \\
\text { sitting exam }\end{array}$ & 48 & 95 & 142 \\
\hline $\begin{array}{c}\text { Total number } \\
\text { who passed }\end{array}$ & 27 & 31 & 129 \\
\hline Percentage & $56.2 \%$ & $32.6 \%$ & $90.8 \%$ \\
\hline
\end{tabular}

\section{Discussion}

This study provides the first review of exam performance of career-grades versus trainee orthopaedic surgeons. It focuses on current challenges and attempts to find some solutions. These findings lend support to the notion that provision of guidance, peer support and problem-based interactive sessions help career-grades surgeons to improve their likelihood of passing the exit exam and hence allow them more opportunities to advance their career should they wish to. One significant measure of the success of such a system is the extent to which participants obtain their Fellowship exam certificates.

We have assumed that language and communication skills and lack of mentoring as possible contributing factors to this discrepancy.Part of the focus of the group has been to correct this, with focus on precise use of language and the higher order thinking required for the exam. The data strongly suggests that if the career-grades are given structured mentoring and teaching but allowed to learn at their own pace and with the use of multiple platforms, the pass rate gap will be significantly narrowed.

The Standing Committee on Postgraduate Medical and Dental Education [5]described mentoring as: 'The process whereby an experienced, highly regarded, empathic person (the mentor), guides another individual (the mentee) in the development and re-examination of their own ideas, learning, and personal and professional development. The mentor who often, but not necessarily, works in the same organisation or field as the mentee, achieves this by listening and talking in confidence to the mentee.

We have found use of the Mentors within the telegram group has provided support to many participants both in developing and guiding study but also in coping with tremendous pressure of the exam and preparation for exam,all mentors have successfully taken the exam and now we have an alumni of mentors who started with the group prior to sitting the exams, and volunteer their time in both structured and non-structured ways. Much of the dissatisfaction with conventional medical education has come about as a result of the pronounced trend of lectures. The lecture method has proven to be unsatisfactory as a principal mode of instruction. Lectures have the potential to vary widely in quality and they often attract low attendances. Thus, educators who use conventional curricula are forced to emphasise an inadequate method of instruction [3].

The non-consultant, career-grade doctors are a diverse and large part of the medical workforce and should be considered as a distinct group [6]. Although some doctors are content and fulfilled in working within their current grade. Significant numbers want to train and progress to a more senior responsibility and productivity within the profession. This would not only benefit the individuals concerned but would also help with the current medical workforce challenges. There is a good deal of support for these doctors although there is variation in this support among hospitals and deaneries across the UK.

Peer-assisted learning has many purported benefits including preparing surgeons as educators, improving communication skills and reducing faculty teaching burden and costs [7]. Another advantage of this comprehensive online mentoring approach is the low cost involved, such as saving on booking lecture rooms and providing catering, and the time saved by not having to travel long distances to attend teaching. 
Thus, it was possible to deliver this teaching to candidates who were geographically spread all over UK, and in fact the world[8]. This smart use of technology has ensured better attendance as location of the candidate is not a hindrance.

The limitations of this study are the small number of candidates following this mentoring problem-based teaching programme who have attempted the exam. However, we noticed increasing interest among the candidates to participate in this programme in view of improving results. We have since started introducing a one to one mentoring to those candidates who have only one last attempt left at the examination, and we will audit the outcome of this programme in due course.

\section{References}

1. Specialist or GP applications (2018) General Medical Council, England.
2. Visser MRM, Smets EMA, Oort FJ, Haes HCJM de (2003) Stress, satisfaction and burnout among Dutch medical specialists. CMAJ Can Med Assoc J168(3):271-275.

3. Albanese MA, Mitchell S (1993) Problem-based learning: a review of literature on its outcomes and implementation issues. Acad Med Assoc Am Med Coll68(1):52-81.

4. Examination Results (2018) JCIE.

5. Nandi PL, Chan JN, Chan CP, Chan P, Chan LP (2000) Undergraduate medical education: comparison of problem-based learning and conventional teaching. Hong Kong Med J Xianggang Yi Xue Za Zhi6(3):301-306.

6. GMC data on doctors working in the UK (2015) General Medical Council, England.

7. Peets AD, Coderre S, Wright B, Jenkins D, Burak K, et al. (2009) Involvement in teaching improves learning in medical students: a randomized cross-over study. BMC Med Educ9:55.

8. Group BMJP (1998) Briefing. BMJ317(7165):S3-7165.
Your next submission with Juniper Publishers will reach you the below assets

- Quality Editorial service

- Swift Peer Review

- Reprints availability

- E-prints Service

- Manuscript Podcast for convenient understanding

- Global attainment for your research

- Manuscript accessibility in different formats

( Pdf, E-pub, Full Text, Audio)

- Unceasing customer service

Track the below URL for one-step submission

https://juniperpublishers.com/online-submission.php 